\title{
A trial of resources to support students with Dyslexia
}

Calum Heraty, Department of Mathematics and Statistics, Maynooth University, Ireland.

Email: calum.heraty@mu.ie

Ciarán Mac an Bhaird, Department of Mathematics and Statistics, Maynooth University, Ireland.

Email: ciaran.macanbhaird@mu.ie

Peter Mulligan, Department of Mathematics and Statistics, Maynooth University, Ireland.

Email: peter.mulligan@mu.ie

James O'Malley, Department of Mathematics and Statistics, Maynooth University, Ireland.

Email: james.omalley@mu.ie

Rachel O'Neill, Department of Mathematics and Statistics, Maynooth University, Ireland.

Email: rachel.oneill@mu.ie

\begin{abstract}
In this paper we report on a pilot of resources to support students with dyslexia conducted at a university in Ireland. We give brief background to the development of these resources and describe the steps taken to pilot them in a mathematics support centre. We outline the feedback received from tutors and students, and close with observations on how the pilot outcomes may influence the future implementation of these and other similar resources.
\end{abstract}

Keywords: Accessibility, dyslexia, resources, mathematics support.

\section{Introduction and Background}

There are increasing numbers of students with disabilities in Higher Education (HE) in Ireland and the UK (AHEAD, 2018; Equality Challenge Unit, 2017) and there is a need to provide appropriate support for these students. In Ireland, the subject area of mathematics and statistics has the third highest proportion of students with a disability (AHEAD, 2018). AHEAD recommend that it is imperative for $\mathrm{HE}$ Institutions to create inclusive environments, providing 'cross-campus initiatives to respond to the ever-diversifying needs of the student populace' (AHEAD, 2018, p. 64). Maynooth University has a high proportion of students who are registered with Maynooth Access Programme (MAP), and students supported include those with disabilities. Each academic department has a MAP Academic Advisor who acts as a point of contact for MAP students with regards to their specific learning needs in the subjects they are taking. The second author has held this role for the Department of Mathematics and Statistics (the Department) for many years. While he often found that MAP students benefitted from standard advice, e.g. how to study mathematics, how to use existing resources etc., he felt that he did not have the training or skills necessary to help mathematics students effectively with their specific learning needs. When sigma (Network for Excellence in Mathematics and Statistics Support) established the Accessibility Special Interest Group (SIG) in 2016, he immediately joined. Details of the SIG are available online (http://www.sigma-network.ac.uk/sigs/accessibility-sig/).

The SIG conducted a survey in Ireland and the UK on staff awareness of the accessibility barriers that students encounter in HE (Cliffe et al., 2019). The SIG also started a project to develop a series of resources specifically for those who co-ordinate and tutor in mathematics support. The initial development of these resources, in the form of advice sheets for mathematics support tutors and 
co-ordinators, was mainly facilitated through meetings of experts in the UK, in the summers of 2018 and 2019. The completion of most resource working drafts was paused until the end of 2020 due to the implementation of certain aspects of accessibility legislation in the UK. A SIG review established that the resources for dyslexia were suitable to be piloted and the second author offered to carry this out at his home institution, Maynooth University. It was left to the authors to conduct the pilot as they saw appropriate, subject to local factors.

The remainder of this report provides details of how we ran the pilot and the circumstances that may have influenced it. We summarise the feedback collated from tutors and students and we close with a brief outline of our plans for 2020-21.

\section{Methodology}

The resources for each accessibility issue come in pairs, one for support tutors (Appendix A) and another for mathematics support managers/co-ordinators/administrators (Appendix B). The manager sheet opens by briefly describing dyslexia. It then details equipment and software that should be available to tutors for helping students. It provides information on suitable physical and virtual learning environments and suggests that both tutor training and coordination with other institutional student services is important to maximise the supports in place for students. The tutor sheet also opens with a brief description of dyslexia and the impact it can have on students. It then lists strengths that students with dyslexia may have. The main part of the sheet lists the impacts that dyslexia can have on the study of mathematics and possible strategies that a tutor might use to address them. Both sheets also have links or references to further information on dyslexia.

In June 2019 we conducted an internal review of the documents in terms of their clarity for practical implementation, and observations are listed in Section 3.1. If a student is registered with the Disability Office, then their module lecturers can view information relevant to the student's learning needs on an internal Maynooth University system. Department tutors, who run the small group tutorials or work in the Mathematics Support Centre (MSC), do not have access to this information and are made aware only if the student requests it or tells the tutor directly themselves. However, students may not be aware that tutors do not have access to this information. The second author met with MAP Disability Office staff to make them aware of the trial and we agreed that students would need to inform support tutors that they would like to use the resources. To create student awareness of the resources, we decided to:

1. Contact MAP students regularly via email and announcements at MAP student events.

2. Ask department tutors to make short announcements in tutorials.

3. Provide an information sheet about the trial to all students who visit the MSC for the first time and put posters on the MSC noticeboards.

4. Verbally remind students in the MSC about the availability of these resources when assisting them.

As students may be reluctant to tell a tutor about their learning needs, when possibly surrounded by their peers, in a public and busy environment (the MSC), we also made students aware that they could e-mail the MSC directly to discuss how best to use the resources in a manner that was comfortable for them. Furthermore, to ensure that the use of these resources in the MSC did not stand out or draw the attention of other users, we decided to introduce packs for the MSC tutors which they would carry with them at all times. These packs contained items that featured in the resource sheets, for example coloured paper, squared paper, post-its, highlighters etc. The tutor 
packs also contained paper which we use when assisting students. So, when helping any student in the MSC, it would be normal for the tutor to open their pack and take out materials.

In order to assess the use of the resources and include the student voice, a feedback sheet (Appendix C) was developed. It was designed for use every time a student requested the resources, and filled in by the tutor and the student simultaneously. It sought to obtain summary information on how dyslexia impacted on the student, which strategies the tutor utilised during their interaction and how students rated these. This feedback sheet was also included in the tutor pack. In an effort to make the feedback process more efficient and minimise disruption to the student learning experience in the MSC, most of the feedback form had 'Yes/No' questions with one Likert-type response, and we added the option of a brief follow up outside the MSC via interview.

The MSC is based in a large room in the library, with seating for around 120 students and operates a drop-in service. During 2019-20, there were typically between 20 and 25 weekly hours of drop-in available before closure due to COVID-19. Drop-in is available to all Maynooth University undergraduates and hours are usually very busy, with weekly attendance of approximately 900 individual visits. In September 2019, as part of MSC training, tutors were informed about the trial, the tutor packs and how to assist students who requested these resources. Tutor participation was optional, but all agreed to partake. The second and third author made sure that resources mentioned in the manager sheet were available for tutors in the MSC. Ethical approval was received for this study and the trial commenced in October 2020 when drop-in sessions commenced.

During the trial, there were a total of six requests from five individual students to use the resources. Feedback was completed on each occasion (Section 3.2), and all five students agreed to be interviewed. The university closure disrupted the planned schedule for interviews, and ultimately we were only able to interview one student (Section 3.3). No students sought to use the resources during the online support sessions provided after the shutdown.

\section{Feedback}

\subsection{Initial Tutor and Manager Feedback}

The observations gathered were positive, and any issues raised were minor, relating to the clarity of understanding of some points. For example, for the strength 'Taking a holistic approach' on the tutor sheet, a tutor stated that 'I don't know what this means or would look like in a maths context'. In relation to the impact 'Reading a mix of text and non-text, finding it difficult to move from text to notation.' and the associated strategy 'Use diagrams where possible', a tutor commented, 'If reading a mixture of text and non-text is a problem I am unsure as to how diagrams help with this rather than make it worse, maybe some elaboration or further explanation is needed.'. Finally, in relation to the impact 'Copying errors' a tutor added that

'I've come across students who said they were dyslexic and they had taken down notes incorrectly during lectures, (they wrote down words that had similar letters but were completely different meanings). So their own notes made no sense to them. When a student is showing you their notes, it might be good to check if their notes are correct and encourage them to cross-check their notes with another student?'.

In relation to the manager sheet, clarity was sought on the meaning of 'rapid naming' in the initial quote. It was also observed that post-its ' ... are not mentioned on the corresponding sheet for tutors.

... Perhaps some guidance on what these would be used for would be good. Coloured paper is also not mentioned on the tutor sheet. Under equipment, more information was sought on what types of 
colour for 'coloured paper' and in the section 'Online Learning Environment', elaboration on the meaning of 'accessible word document' was sought.

\subsection{Student and Tutor Implementation Feedback}

We describe the six interactions in random order. Participant I was in first year. 'Copying Errors' e.g. switching digits or signs was the impact and strategy $G$ 'Squared Paper' was used. Participant II was a postgraduate taking some undergraduate modules. 'Read the question text' and 'Reading, remembering and recalling information' were identified as impacts. Strategies C 'Use of colour for different aspects of a problem', D 'Use bullet points to break up text' and J 'Write down what you [the tutor] say as the student will be likely to not recall this' were the strategies used. Participant III was a second year and 'reading the question text' was the impact identified. The tutor used strategy $B$ 'Highlight key points in the material' but noted that they also made use of $F$ 'Use diagrams where possible', G and J.

Participant IV was in first year. For the impact 'Taking notes at speed', J was used, for impact 'Reading the question text, having to read several times to gain meaning', C and D were used, and for impact 'getting lost in the middle of the problem', F was used. All four participants rated the effectiveness of the strategies used as 'very good'. Participant IV used the resources on a second occasion. This time a specific impact was not listed but the tutor 'used coloured paper (yellow). Text is easier to read for the student on yellow paper'. While this was not a strategy listed, the MSC was supplied with a range of different coloured paper as this featured on the manager sheet. The effectiveness was rated 'good'. Participant $V$ had impacts 'getting lost in the middle of the problem' ( $F$ used), and 'reading remembering and recalling' ( $B$ and J were used). Strategy F's effectiveness was rated as 'very good' and strategies B and J were rated as 'neutral'.

All five students indicated that they were willing to be contacted for a follow up on the trial, and that they were aware of and registered with MAP.

\subsection{The Student Interview}

Only Participant III was available for interview, which was conducted via Microsoft Teams by the first author and lasted for approximately 10 minutes. We present a brief summary.

Participant III responded positively to their experience of using the resources in the MSC. The student commented that the MSC was well-equipped to meet students' needs, 'I think for the dyslexia and that, they had the right tools for helping people'. The specific resources that benefitted the student included the use of coloured paper to help focus on the question, 'I think the coloured paper just makes the words pop out a bit more and makes it more understandable' and writing down the steps on how to approach the question. The student reported that they further applied the latter approach outside the MSC when attempting questions. The student endorsed the in-person implementation of the resources by the MSC and suggested it could be made available online. They added that dyslexia most impairs their reading and interpretation of questions and putting down on paper what they want to do. The student reported that they had not received any specific resource support for dyslexia in secondary school or in Maynooth University, and that they would like to see the resources provided by the MSC implemented by other academic departments within Maynooth University. The student's final comments referred to the MSC's general supports and effectiveness, 'I wasn't really that good at the maths but I found [attending] the support centre really boosted my grade'. The student indicated they would be willing to continue using the resources for dyslexia upon returning to the MSC. 


\section{Conclusion and Future Work}

The 2019-20 academic year was, in hindsight, perhaps not the best time to pilot a new resource. Covid-19 and other local Maynooth University decisions had a major impact on MSC opening hours and tutor numbers, and this certainly influenced student engagement and feedback (interviews). Also, as the students filled out the feedback forms with the tutors who helped them in the MSC, it is possible this influenced their responses. A larger study would be required to give further details on the resources which worked particularly well, and identify any which are less effective. Nevertheless, we are glad to have had this opportunity and hope that this preliminary report is of benefit to those in the wider mathematics support community hoping to use these and similar resources.

We have given the feedback to the SIG leads, and have recommended that when the finalised resources are placed on the sigma website, they be accompanied by a FAQ sheet which addresses many of the queries raised in Section 3.1. As such, we believe that as further resources are released, it is important that they are piloted.

We intend to continue using the dyslexia resources and will incorporate some changes. We will circulate the sheet to MSC tutors in advance of tutor training to enable queries to be discussed and addressed during training. We have not yet decided if we will continue to use the evaluation sheet, as it did interrupt the fluidity of the mathematics support that the tutor was providing to the student.

The biggest local challenge we face is trying to ensure that more students with dyslexia seek to use this resource, and this is something that we will try to progress via discussions with MAP staff.

In terms of the other accessibility resources, those for Dyscalculia and Dyspraxia are ready (August 2020) but both require the Maths Anxiety resource which is not yet finalised. The SIG aims to complete this resource, and others e.g. autism, hearing impairment, visual impairment etc. as soon as possible. Maynooth University is happy to pilot these resources as they become available and would encourage other institutions to also get involved.

\section{Acknowledgements}

The trial of these resources is part of the ICT and STEM Enhancement Project at Maynooth University funded by the HEA. Ciarán Mac an Bhaird is the lead on the Mathematics strand of this project, and James O'Malley and Rachel O'Neill's positions are fully funded by the HEA.

\section{References}

AHEAD Educational Press. 2018 Numbers of Students with Disabilities Studying in Higher Education in Ireland 2016/17. Available at: https://www.ahead.ie/data-statistics?id=76 [Accessed 4 August 2020].

Cliffe, E., Mac an Bhaird, C., Ní Fhloinn, E. \& Trott, C., 2019. Mathematics instructors' awareness of accessibility barriers for disabled students. Teaching Mathematics and its Applications: An International Journal of the IMA, https://doi.org/10.1093/teamat/hrz012

Equality Challenge Unit. 2017 Equality in higher education: students statistical report 2017. Available at: $\quad$ https://www.ecu.ac.uk/publications/equality-in-higher-education-statistical-report-2017/ [Accessed 4 August 2020]. 


\section{Appendix A:}

\section{For tutors: Dyslexia (draft summer 2019) Introduction}

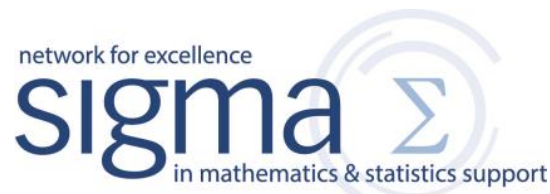

Dyslexia is lifelong. It can impact on reading, spelling, working memory and organisation. Dyslexia encompasses a spectrum of difficulties that can affect learners in different ways. Some learners will have strong mathematical skills but struggle with accessing and communicating information. Others may struggle with arithmetical procedures and foundational understanding.

The dyslexic student may have some of the following strengths:

- Visual thinking

- Taking a holistic approach (looking at the larger mathematical context)

- Thinking outside the box

- Problem solving

- Good at mathematics

- Preference for conceptual fluency over procedural fluency

\section{Possible Impacts on Mathematics (suggested strategies in brackets)}

- Reading the question text, having to read several times to gain meaning $(A, B, C, D)$

- Reading a mix of text and non-text, finding it difficult to move from text to notation $(A, B, C, D, F)$

- Reading, remembering and recalling new technical words (B, E, J)

- Taking notes at speed while a tutor is talking $(E, J)$

- Difficulty documenting a full solution $(\mathrm{H})$

- Aligning digits (G)

- Copying errors, e.g. switching digits or signs $(G, I, J)$

- Remembering and recalling notation, maths facts and procedures $(B, E)$

- Getting lost in the middle of a problem (C, F, H)

\section{Strategies to Help}
A. Allow time for the student to read
B. Highlight key points in the material
C. Use of colour for different aspects of a problem, e.g. different variables
D. Use bullet points to break up the text
E. Make a list or glossary of technical words, symbols or notation
F. Use diagrams where possible
G. Use squared paper
$\mathrm{H}$. Encourage the student to write down all their working in an orderly way
I. Encourage the student to check for mistakes
J. Write down what you say as the student will be likely to not recall this

\section{Further information}

Further assistance on time management, organisational and other study skills can be accessed from your Disability Department or relevant Student Support.

Further information from Trott C. (2012) Mathematics, dyslexia, and accessibility. In Good Practice on Inclusive Curricula in the Mathematical Sciences, Ed. Cliffe E and Rowlett P. January 2012. pp 26-30, http://www.mathcentre.ac.uk/resources/uploaded/inclusivecurricula.pdf 


\section{Appendix B:}

For Managers: Dyslexia

(draft summer 2019)

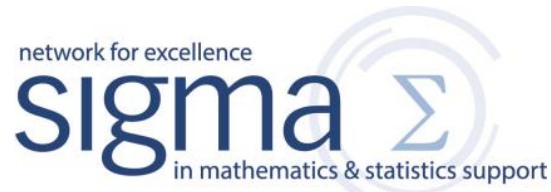

\section{Further introduction}

"Dyslexia is likely to be present at birth and to be lifelong in its effects. It is characterised by difficulties with phonological processing, rapid naming, working memory, processing speed and the automatic development of skills that may not match up to an individual's other cognitive abilities. It tends to be resistant to conventional teaching methods, but its effects can be mitigated by appropriately specific intervention..." (BDA, 2007)

A dyslexic student thinks in different ways, often more visually and can have good insight. They are frequently good mathematicians. However, there will be some issues with reading, writing or memory.

\section{Recommended provision}

\section{Equipment and software}

It is recommended that you have the following equipment available for helping students with dyslexia:

- Highlighters

- Coloured paper

- Squared paper

- Post-its

- 2-line calculators (which display input and output)

There are a wide range of softwares which students may use for assistance. The website (http://stemenable.referata.com/wiki/Welcome to STEM Enable), currently under construction, will maintain an up-to-date description of softwares and their functionalities. If a student is using a specific software, and you need further guidance, we recommend that you liaise with relevant support staff, e.g. in the Disability Office.

\section{Physical learning environment}

A quiet space to work is helpful.

\section{Online learning environment}

Provide documents in a format which can be transformed to meet the reader's needs and which can be read aloud and colour annotated, including the equations. Accessible Word documents and accessible web pages are best. Guidelines will be available from sigma (http://www.sigma-network.ac.uk/) soon. Provide materials in a choice of formats, e.g. the same concept explained in video, via interactive example and in text.

\section{Additional/alternative provision}

Think about providing 1:1 support. 


\section{Tutor training}

We recommend that you include a discussion on these Manager and Tutor leaflets in tutor training at your institution. Over the coming years, accessibility training will become an important feature of maths support tutor training at local and national levels. For further information on tutor training, contact your maths support network.

\section{Working with other university services}

It is important to know the Disability Department in your institution who can supply further details about dyslexia.

- You should have information leaflets about the Disability Department available for students in your centre and vice versa.

- The Disability Department may also be able to recommend that other students use your maths support centre.

- If you think a student in your centre has dyslexia, you should encourage and support the student to make contact with the relevant Disability Department in your institution.

\section{Recommended reading}

Trott C. (2012) Mathematics, dyslexia, and accessibility. In Good Practice on Inclusive Curricula in the Mathematical Sciences, Ed. Cliffe E and Rowlett P. January 2012. P. 26-30 http://www.mathcentre.ac.uk/resources/uploaded/inclusivecurricula.pdf

Some basics are covered in the 2003 Good Practice in the Provision of Mathematics Support Centres (http://www.mathcentre.ac.uk/resources/guides/goodpractice2E.pdf) p22-27

Hunter-Carsch M and Herrington M (2001) Dyslexia and Effective Learning. Whurr, London

Henderson A (2012) Dyslexia, Dyscalculia and Mathematics. Routledge, Oxon.

Du Pre L, Gilroy D. and Miles T.R. (2008) Dyslexia at College. Routledge, Oxon. 


\section{Appendix C:}

Date:

Tutor Name:

\section{MSC Dyslexia Resource Feedback Sheet}

This is the first part of an international project to develop a range of resources available for students. In order to refine and improve the resources, student feedback is essential. However, feedback is optional. The feedback below can be provided anonymously if the student prefers. All information provided will be strictly confidential and held securely.

\section{Student No.}

(optional)

(Student number would allow us to identify the frequency of use of the resources. Individual students will not be identified in any reporting of this information.)

\begin{tabular}{|c|c|c|c|c|c|}
\hline 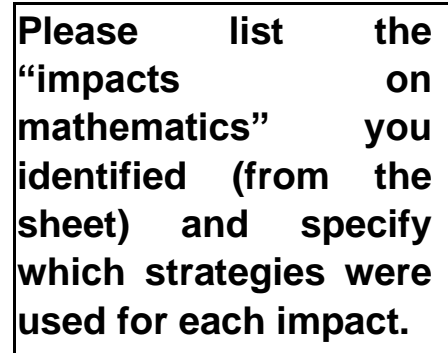 & & & & & \\
\hline $\begin{array}{l}\text { How would you rate } \\
\text { the effectiveness of } \\
\text { the resources? }\end{array}$ & Very Poor & Poor & Neutral & Good & Very Good \\
\hline
\end{tabular}

(These are to be completed by the student and tutor together)

Are you willing to be contacted in future for a brief follow up on this trial?

Yes

No

The MAP office (Maynooth University access programme) offers a wide range of supports which are freely available to students with learning difficulties.

\begin{tabular}{|l|c|c|}
\hline Is the student aware of MAP? & Yes & No \\
\hline $\begin{array}{l}\text { Is the student registered with } \\
\text { MAP? }\end{array}$ & Yes & No \\
\hline $\begin{array}{l}\text { If not, is the student interested } \\
\text { in meeting with MAP? }\end{array}$ & Yes & No \\
\hline
\end{tabular}

MAP Academic Advisor for the Department of Mathematics and Statistics, Dr. Ciarán Mac an Bhaird, normally emails MAP on the student's behalf to arrange an introduction (the student will be cc'd in the email). 